\title{
How strategic orientations influence the building of dynamic capability in emerging economies ${ }^{\hbar}$
}

\author{
Kevin Zheng Zhou ${ }^{\mathrm{a}, *}$, Caroline Bingxin $\mathrm{Li}^{\mathrm{b}, 1}$ \\ a Dept of Marketing, Belk College of Business, University of North Carolina at Charlotte; Charlotte, NC 28223, United States \\ b School of Business, The University of Hong Kong, Pokfulam, Hong Kong
}

\section{A R T I C L E I N F O}

Article history:

Received 1 April 2008

Received in revised form 1 December 2008

Accepted 1 March 2009

Available online $\mathrm{xxxx}$

\section{Keywords:}

Strategic orientation

Dynamic capability

Adaptive capability

Emerging economies

China

\begin{abstract}
A B S T R A C T
Under the fierce pressures of the fast changing environments that characterize emerging economies, firms must develop dynamic capabilities to survive the competition. This study examines how strategic orientation helps build dynamic capability and its contingencies in China's emerging economy. A survey of 380 firms indicates strategic orientations are important drivers of adaptive capability, a key element of dynamic capabilities. The effectiveness of strategic orientations is contingent on market dynamics. In particular, when market demand becomes increasingly uncertain, customer orientation has a weaker impact, whereas technology orientation has a stronger effect on adaptive capability. As competition intensifies, both competitor and technology orientations build adaptive capability more effectively.
\end{abstract}

(c) 2009 Elsevier Inc. All rights reserved.
During their economic reform processes, emerging economies experience massive, complex changes in their institutions, including government, economic systems, enterprise ownership structures, market environment, and so forth, which creates serious strategic challenges for businesses seeking opportunities (Li et al., 2009). For example, most industries in China undergo deep structural transformation characterized by high structural uncertainty, escalating competitive pressures, and unbalanced growth as a result of industrial policies and regulation. Such dynamics significantly shape managerial assumptions, criteria, and decision making (Zhou et al., 2006).

To face this challenge, some researchers propose that firms must develop dynamic capabilities to renew, reconfigure, and adapt existing firm-specific resources in response to the fast changing environment (Teece et al., 1997). Because building dynamic capabilities requires internal processes and efforts rather than acquisitions from market transactions, they are the most unique and difficult-to-imitate assets a firm can use to achieve and sustain competitive advantage (Griffith and Harvey, 2001). Developing a dynamic capability is especially important for companies in emerging economies, given their turbulent and unprecedented environments. However, despite growing interest in the dynamic capability perspective, most studies remain theoretical and conceptual and call for more empirical research to examine and validate

\footnotetext{
is This study was supported by a research grant from the University of Hong Kong (HKU 07176022).

* Corresponding author. Tel.: +1 704687 7672; fax: +1 7046876463

E-mail addresses: K.Zhou@uncc.edu (K.Z.Zhou), bingxinli@business.hku.hk (C.B. Li)

1 Tel: +852 2241 5344; fax: +852 28585614 .
}

this perspective (Lavie, 2006). As a result, discussions of how firms build dynamic capabilities remain underdeveloped.

Strategic orientation as a strategic choice may provide a source that helps firms build dynamic capabilities in fast changing environments. Recent strategic marketing literature pays special attention to strategic orientation as a significant driver of superior performance in emerging economies (for a review, see Zhou and Li, 2007). Strategic orientation focuses on how firms should interact with external environments such as customers, competitors, and technology to conduct business (Day, 1994; Gatignon and Xuereb, 1997). As such, strategic orientation reflects an outward-looking view of the fit between strategic choices and environment. In contrast, dynamic capability is inward looking, focusing on how to integrate and rejuvenate firm resources. Therefore, strategic orientation as a strategic choice should drive the way firms acquire, allocate, and utilize resources to create dynamic capabilities. As a result, an integration of these two approaches provides new insights into how strategic choice affects internal processes, such as resource reconfiguration and modification. However, extant literature does not touch on the role of strategic orientation in building dynamic capability, which represents a significant research gap.

The effectiveness of firm strategy depends on the fit between strategic choices and market dynamism (Ginsberg and Venkatraman, 1985). Accordingly, the effects of strategic orientation may be contingent on the dynamics of the environment (Day and Wensley, 1988). However, limited research investigates such contingencies in emerging economies, and even previous findings based on the context of developed economies are largely equivocal (Kirca et al., 2005). For instance, whereas some studies support the positive role of customer orientation (Han et al., 1998; Slater and Narver, 1994), others caution that it exerts a 
negative influence in an artistic environment (Voss and Voss, 2000). Zhou et al., (2007) find that customer and competitor orientations have differential effects in developed versus developing markets. Therefore, integrating the contingency view is necessary to further understanding of how strategic orientations drive dynamic capability in emerging economies.

To address these research gaps, this article examines the effects of strategic orientations on dynamic capability in the emerging economy of China by focusing particularly on a key element of dynamic capability, adaptive capability, and studying how strategic orientations (namely, customer, competitor, and technology orientation) influence adaptive capability. Moreover, this article examines whether the strategic orientation-adaptive capability relationship depends on market dynamics (i.e., demand uncertainty and competitive intensity). As such, this research contributes to existing literature by integrating an outward-looking perspective (i.e., strategic orientation) with an inwardlooking view (i.e., dynamic capability), scrutinizing their contingency effects, and examining those relationships in a new and challenging empirical context (emerging economies).

\section{Conceptual development}

\subsection{Dynamic capability perspective}

The resource-based view (RBV) proposes that competitive advantage is primarily driven by a firm's valuable, rare, inimitable, and nonsubstitutable resources. Although the RBV as a theoretical framework helps explain how firms achieve competitive advantage, the theory does not adequately detail how firms achieve competitive advantage in the context of fast changing environments (Eisenhardt and Martin, 2000). Because resources are context based, their values depend on the characteristics of the given environment; because resources also are relatively stickier than their environment, resource changes and adaptations often lag behind environmental changes (Teece et al., 1997). Therefore, in rapidly changing markets, a dominant focus on core resources may create rigidities that prevent firms from adapting their resources to the new competitive environment (Leonard-Barton, 1992).

Scholars thus extend the RBV further to the dynamic capability perspective, stressing the critical role of capabilities to "integrate, build and reconfigure internal and external competencies to address rapidly changing environments" (Teece et al., 1997, p. 516). From this perspective, firms must adapt, integrate, and reconfigure their resources and competencies continuously in response to changing market conditions; however, entrenched organizational processes and routines, developed from previous paths or the trajectory of resource allocation and competence development, constrain those changes or adaptations (Teece et al., 1997). Recent studies further develop and clarify the concepts of dynamic capabilities. For example, Benner (2006) proposes that responsiveness to technological changes represents an element of dynamic capabilities in the digital photography industry setting (see also Griffith et al., 2006).

Consistent with previous research, this study views effective adaptation to a changing environment (i.e., adaptive capability) as the key element of dynamic capabilities. Adaptive capability reflects a firm's ability to reconfigure resources and coordinate processes promptly and effectively to meet rapid environmental changes (Gibson and Birkinshaw, 2004) and thereby captures the essence of dynamic capabilities. Absorptive capacity, the ability to assimilate and utilize new knowledge acquired from external sources, is a related yet distinct element of dynamic capability (Cohen and Levinthal, 1990; Lenox and King, 2004; Tsai, 2001). Whereas adaptive capability emphasizes the reconfiguration of resources and processes to respond to external changes (Gibson and Birkinshaw, 2004), absorptive capability as a learning-based ability focuses on knowledge assimilation and utilization (Tsai, 2001). Firms with a high level of absorptive capacity likely harness new knowledge to enhance their innovative activities (Zaheer and Bell, 2005). Hurley and
Hult (1998) also suggest that adaptive capability provides a competitive advantage, especially in turbulent environments. Therefore, methods for building adaptive capability represent critical issues for firms operating in emerging economies.

In their conceptual development, Mckee et al. (1989) posit that strategy types, such as reactor, defender, analyzer, and prospector, affect the increasing levels of adaptive capability. Tuominen et al. (2004) argue that dominant business logics (e.g., market-based, technology-based) influence the level of adaptive capability (e.g., technology searching, global market monitoring). Consistent with previous research, this study postulates that firm strategic orientation drives adaptive capability. According to the dynamic capability perspective, because successful adaptation to internal and external pressures requires organizational slack or surplus, firm resources limit the level of adaptive capability a firm can achieve (Teece et al., 1997). Strategic orientation guides the way a firm interacts with external entities, such as customers, competitors, and technology (Gatignon and Xuereb, 1997), and thus influences the relative emphasis the firm puts on resource acquisition and allocation, and consequently, its adaptive capability development.

Following Gatignon and Xuereb (1997), this study views strategic orientation as a multidimensional construct consisting of three distinct orientations: customer, competitor, and technology (see also Voss and Voss, 2000). Customer orientation emphasizes the sufficient understanding of target customers' changing preferences and places the highest priority on creating superior value for customers continuously; competitor orientation focuses on understanding competitors' strengths and weaknesses and monitoring their activities; technology orientation believes that consumers prefer technologically superior products and firms should keep a close watch on technological changes and heavily invest resources to catch up with state-of-the-art technologies (Gatignon and Xuereb, 1997; Narver and Slater, 1990; Voss and Voss, 2000). The following sections examine how each of the three orientations affects adaptive capability and the contingency effects on environmental dynamics.

\subsection{Strategic orientation and adaptive capability}

Customer-oriented firms show a continuous, proactive disposition toward identifying and meeting customers' expressed and latent needs (Han et al., 1998). With customer-oriented values, firms excel in creating and maintaining bonds with customers and obtain timely feedback from them. When customer needs change rapidly, customer orientation enables firms to recognize those changes and guides them to invest necessary resources to develop appropriate new products or services, refine production processes, and offer a flexible product line to cater to customers' changing preferences (Slater and Narver, 1998). As a result, customer-oriented firms can adapt to market changes effectively.

By actively collecting competitor-related information and monitoring rivals' behavior, competitor-oriented firms identify their strengths and weaknesses in comparison with their competitors in terms of resources, cost position, and financial performance (Day and Wensley, 1988). With a deep understanding of rivals, a firm can assess its position, determine appropriate strategies, and respond quickly to competitors' actions. Because the objective of a competitor-centered approach is to keep pace with or remain ahead of competitors (Han et al., 1998), a competitor orientation can facilitate firms' capability to adapt to the changing environments. In addition, a competitor orientation helps firms configure or reconfigure their resources while collecting competition-related information and developing capabilities to cope with competitive environments.

Finally, firms guided by a technology orientation accumulate rich technological knowledge stores through past experience and processes, such as heavy investments in R\&D, quick acquisition of new technologies, and collection of up-to-date technology information. Such proficiency not only facilitates firms' ability to exploit existing competencies in refining technology and differentiated products to respond 
to market changes (Gatignon and Xuereb,1997) but also enables them to recognize emerging or potential technological trends and reconfigure resources to capitalize on those opportunities (Zhou et al., 2005). Therefore, technology orientation should enhance adaptive capability.

$\mathrm{H}_{1 a}$ : Customer orientation increases adaptive capability.

$H_{1 b}$ : Competitor orientation increases adaptive capability.

$\mathrm{H}_{1 c}$ : Technology orientation increases adaptive capability.

\subsection{Contingency effects of market dynamics}

The effectiveness of any strategic orientation likely depends on market dynamics (Jaworski and Kohli, 1993). Among the various dimensions of market dynamics, demand uncertainty and competitive intensity represent the two most fundamental, because they reflect the influence of key players in the market: customers and competitors (Voss and Voss, 2000).

Demand uncertainty refers to heterogeneity and instability in customer preferences (Gatignon and Xuereb, 1997). When customer preferences are stable, a customer orientation is unnecessary, because the firm does not need to monitor preference changes. When customer demand is moderately uncertain, a customer orientation can enhance firms' ability to understand customers' expressed and potential needs and modify products and services accordingly (Slater and Narver, 1998). These customer-oriented efforts improve firms' ability to adapt to demand changes. However, when market demand is highly uncertain, monitoring customers may not enable firms to identify or predict what customers really need, because customer needs change so rapidly that even customers themselves may not know what they want (Von Hippel, 1988; Workman, 1993). Thus, intelligence generated from customers may not provide insights into how to redeploy resources and adapt product offerings to handle or cope with fast changing customer preferences. Furthermore, customer demands impel patterns of resource allocation within customer-oriented firms. However, because customers generally focus on their existing needs and cannot foresee market trends, customer-centered firms may risk overlooking emerging opportunities and relocating resources to a wrong track. As a result, when customer preferences change rapidly, those firms' strategic moves may lag behind market changes and fail to adapt effectively due to their incorrect trajectory of resource allocation (Christensen and Bower, 1996). In the fast changing environment of the Chinese market, demand uncertainty overall is relatively high (i.e., ranges from moderate to very high) (Zhou et al., 2005). Therefore, the positive effect of customer orientation on adaptive capability is weaker when demand uncertainty is high.

$\mathrm{H}_{2 a}$ : The greater the demand uncertainty, the weaker is the effect of customer orientation on adaptive capability.

When market demand is highly uncertain, companies turn to competitors for more insightful information. Learning from competitors' information and intelligence enables firms to understand competitive actions and industry trends (Day and Wensley, 1988). With up-to-date knowledge of the competitive landscape, competitororiented firms can diagnose competitors' offerings thoroughly and then manage resource flows to develop improved products to address target customers' needs. Moreover, through an in-depth understanding of potential industry trends, competitor-oriented firms redeploy resource bases at the appropriate scale and pace to adapt to emerging changes (Hamel and Prahalad, 1994). As a result, competitor-oriented firms are better prepared to reconfigure their existing resources to develop appropriate product offerings and cope with changing customer preferences.

$\mathrm{H}_{2 b}$ : The greater the demand uncertainty, the stronger is the effect of competitor orientation on adaptive capability.

In times of high demand uncertainty, a technology orientation may be risky, because heavy $R \& D$ investments commit the firm to a particular technological path. However, a technology orientation also may become more prominent in building the adaptive capability to address uncertain demands: Instead of trying to guess and follow customers' fast changing preferences, technology-oriented firms can handle uncertainty by shaping and leading market demand through the introduction of advanced technology and new product (Workman, 1993). Apple's iPhone serves as a case in point. The cell phone market is full of uncertain demand, including consumers who replace their phones frequently and new models introduced almost every month. As a new player in this volatile market, Apple did not follow what the others were doing but rather introduced a revolutionary new concept to inspire and lead customer needs by converging a novel user interface technology, advanced software, and breakthrough Internet devices (BusinessWeek, 2007). Gatignon and Xuereb (1997) support this reasoning with their finding that a technology orientation plays a more effective role when demand is highly uncertain. Furthermore, technology-oriented firms excel in technological knowledge accumulation and application, which enable them to coordinate resources efficiently in terms of flexible product design and production processes, as well as experiment with new ideas to gain an early lead in emerging demand trends (Zahra and George, 2002).

$\mathrm{H}_{2 c}$ : The greater the demand uncertainty, the stronger is the effect of technology orientation on adaptive capability.

Competitive intensity refers to the degree of competition in an industry (Porter, 1985). In a market in which competition is intense, customers have many alternatives to satisfy their needs (Jaworski and Kohli, 1993), and firms must monitor and respond to customer needs closely to ensure that customers choose their offerings over competitive products (Porter, 1985). As a result, customer orientation becomes more effective for guiding firms' resource reconfigurations and adaptations in highly competitive markets. Atuahene-Gima's (1995) finding provides indirect support for this logic by showing that competitive intensity strengthens the effects of market orientation on new product development. Thus, customer orientation should be more influential in building adaptive capability in highly competitive markets.

$H_{3 a}$ : The greater the competitive intensity, the stronger is the effect of customer orientation on adaptive capability.

Day and Wensley (1988) view a strong competitor orientation as imperative for the success of firms operating in highly competitive markets. When the market is highly competitive, companies must watch their competitors closely to understand their relative standing in the marketplace compared with that of competitors (Han et al., 1998). The enhanced understanding of competitors prompts firms to anticipate and respond to competitors' actions, facilitates firms' ability to calibrate the requirements for change or effect necessary adjustments ahead of competitors (Teece et al., 1997), and thereby helps them adapt to market shifts promptly and appropriately. Insights from close interactions with competitors also provide guidance on how to select, subtract, and reconfigure resources that may amount to a relative advantage against major competitors, which enable firms to effectively handle and actively adapt to intensively competitive conditions (Makadok, 2001). Therefore, competitor orientation should be more prominent in developing adaptive capability in highly competitive markets.

$H_{3 b}$ : The greater the competitive intensity, the stronger is the effect of competitor orientation on adaptive capability.

When competition becomes fierce, locating sources of a defensible, hard-to-duplicate competitive position becomes critical (Rumelt et al., 1991). Technology orientation may provide one such source. First, technological development drives competition, and radical technological advances can fundamentally change the landscape of competition in an industry and create overwhelming competitive advantages (Tushman and Anderson, 1986). Technology-oriented firms can capitalize on the tremendous power of advanced technology to adapt actively to the fiercely competitive market. For example, superior technology-sensing capabilities can direct organizational resource assortments toward continuous product innovations that 
Table 1

Basic descriptive statistics of the constructs.

\begin{tabular}{|c|c|c|c|c|c|c|c|c|c|c|}
\hline Construct & 1 & 2 & 3 & 4 & 5 & 6 & 7 & 8 & 9 & 10 \\
\hline Adaptive capability & 1 & & & & & & & & & \\
\hline Customer orientation & $.27^{* *}$ & 1 & & & & & & & & \\
\hline Competitor orientation & $.13^{*}$ & $.35^{* *}$ & 1 & & & & & & & \\
\hline Technology orientation & $.28^{* *}$ & $.43^{* *}$ & $.31^{* *}$ & 1 & & & & & & \\
\hline Demand uncertainty & .06 & -.02 & .05 & .06 & 1 & & & & & \\
\hline Competitive intensity & $-.18^{* *}$ & -.02 & .01 & .00 & $.49^{* *}$ & 1 & & & & \\
\hline Technology turbulence & .08 & $.22^{* *}$ & .09 & $.32^{* *}$ & $.13^{* *}$ & .03 & 1 & & & \\
\hline Firm size & $.11^{*}$ & -.02 & -.09 & .02 & $-.19^{* *}$ & -.10 & -.01 & 1 & & \\
\hline Industry type & .03 & -.00 & -.03 & -.02 & .02 & -.03 & $.10^{*}$ & $.24^{* *}$ & 1 & \\
\hline Firm type & .03 & $-.12^{*}$ & .03 & -.02 & .08 & .03 & -.03 & $-.16^{* *}$ & -.08 & 1 \\
\hline Mean & 5.3 & 6.0 & 5.8 & 5.1 & 3.7 & 4.2 & 5.5 & 2.9 & 0.4 & 0.4 \\
\hline Standard deviation & 0.9 & 0.7 & 0.8 & 1.0 & 1.4 & 1.4 & 0.9 & 0.7 & 0.5 & 0.5 \\
\hline
\end{tabular}

${ }^{* *} p<.01,{ }^{*} p<.05$. Decimals omitted.

distinguish the firm from its competitors. Second, a technology orientation emphasizes the coordination of technological knowledge and flexible module design mechanisms, which require crossfunctional cooperation and knowledge flows. Thus, firms can better reconfigure their resources to break down institutionalized processes and catch up with emerging technologies, resulting in a stronger ability to adapt to the changing environments (Gilbert, 2005).

$\mathrm{H}_{3 \mathrm{c}}$ : The greater the competitive intensity, the stronger is the effect of technology orientation on adaptive capability.

\section{Method}

\subsection{Sample and data collection}

The sample consists of 420 firms at the strategic business unit (SBU) level in consumer product categories from 20 major cities in China. The sample collection employs a multistage procedure. First, a national research firm provided a sampling frame of the SBUs of 2260 firms from 48 consumer product categories (both durable and nondurable). Second, this study followed a stratified random sampling method in brand selections to rank order all companies within each product category and divide them into two groups on the basis of market share. The first group includes the top 10 firms with the highest market share, and the second group includes all the rest. Third, this study selected at least three companies randomly from each group in each product category to ensure that the sample possesses sufficient performance variance.

With the assistance of the marketing research firm that provided the sample, the study process identified one senior manager as the key informant from each firm, after a screening procedure to ensure that he or she possessed well-rounded knowledge about the firm. Then, an interviewer made appointments with the key informant in each firm for onsite interviews and, before each interview, informed respondents about the confidentiality of their responses and the academic purpose of the study. Then, interviewers presented the questionnaire and asked respondents each question. This procedure ensures an effective response rate and quality control of the data, especially for surveys conducted in emerging economies (Li et al., 2008). These efforts generated a highly successful response rate: a total of 380 usable questionnaires for a response rate of $90.5 \%$. Among the 380 firms, $25.6 \%$ are state owned, $34.7 \%$ are private or joint-stock firms, and $39.7 \%$ are Chinese-foreign joint ventures. The firms represent six major manufacturing industries: electrical appliances (18.3\%), IT (17.4\%), clothes and shoes (15.2\%), food and beverages (24.8\%), household cleaning products (15.1\%), and cigarettes and liquors (9.2\%).

\subsection{Measures}

This project prepared the measures in English and then translated them into Chinese following the back-translation process for accuracy.
Face-to-face interviews with 10 senior managers who had extensive business experience in China served as the pretest of the questionnaire. This pretest suggested revisions of a few items to ensure the face validity and appropriateness of the measures in the Chinese context. The measures used for the constructs in the model, mostly derived from previous research but some developed for this study, appear in the Appendix.

\subsubsection{Strategic orientation}

Consistent with Gatignon and Xuereb (1997), strategic orientation consists of three subconstructs: customer, competitor, and technology orientations. The measures of customer and competitor orientations use items adopted from Narver and Slater (1990), and technology orientation uses a four-item measure adapted from Gatignon and Xuereb (1997), which captures firms' willingness and readiness to pursue and accept state-of-the-art technologies.

\subsubsection{Adaptive capability}

This study develops a four-item measure of adaptive capability on the basis of the conceptual work of Chakravarthy (1982), Lavie (2006), and Mckee et al. (1989). The first item stresses firms' ability to take appropriate actions to respond to market shifts, a key characteristic of adaptive capability (Chakravarthy, 1982; Mckee et al., 1989). The second item gauges firms' potential to keep their competitive advantages in the face of industrial changes by adapting their existing capabilities (Lavie, 2006). The final two items appraise adaptive capability in terms of a firm's ability to cope with specific challenges rising from the Chinese market, such as its entry into the World Trade Organization, and the threats associated with electronic commerce trends. We verify the measure of adaptive capability by testing performance implications. Firm performance equals relative performance in sales growth, return on investment, profit level, and market share in comparison with major competitors (Gatignon and Xuereb, 1997). The results show that an adaptive capability has a positive, direct impact on firm performance $(\mathrm{b}=.401, p<.001)$. Therefore, in emerging economies, firms armed with high adaptive capability effectively can cope with environmental changes and achieve superior performance.

\subsubsection{Market dynamics}

To measure the two components of market dynamics (i.e., demand uncertainty and competitive intensity), this study uses items adapted from Jaworski and Kohli (1993). The items for demand uncertainty assess the uncertainty created by variability in customers' preferences and expectations. The items for competitive intensity appraise the extent of competition in general, competitive imitation, and price wars.

\subsubsection{Control variables}

This study includes four control variables: firm type, firm size, industry type, and technology turbulence. Firm type is a dummy variable, such that 
Table 2

Standardized estimates: multiple moderated regressions (H1-H3).

\begin{tabular}{|c|c|c|c|c|}
\hline \multicolumn{5}{|l|}{ Dependent variable: adaptive capability } \\
\hline Variables & Model 1 & Model 2 & Model 3 & Model 4 \\
\hline \multicolumn{5}{|l|}{ Control variables } \\
\hline Firm size & $.122 *$ & $.137^{* *}$ & $.143^{* *}$ & $.135^{*}$ \\
\hline Firm type & .048 & .063 & .087 & .075 \\
\hline Industry type & .001 & .004 & .003 & .001 \\
\hline Technological turbulence & .081 & -.044 & -.072 & -.053 \\
\hline \multicolumn{5}{|l|}{ Market dynamics } \\
\hline Demand uncertainty (DU) & & $.212^{* * *}$ & $.193^{* * *}$ & $.217^{* * *}$ \\
\hline Competitive intensity (CI) & & $-.271^{* * *}$ & $-.262^{* * *}$ & $-.290 * * *$ \\
\hline \multicolumn{5}{|l|}{ Strategic orientation dimensions } \\
\hline H1a: Customer orientation (CUS) & & $.198^{* * *}$ & $.209^{* * *}$ & $.209^{* * *}$ \\
\hline H1b: Competitor orientation (COM) & & .010 & .007 & .015 \\
\hline H1c: Technology orientation (TO) & & $.193^{* * *}$ & $.201^{* * *}$ & $.177^{* * *}$ \\
\hline \multicolumn{5}{|l|}{ Interaction effects } \\
\hline H2a: CUS $\times$ DU & & & $-.165^{* *}$ & \\
\hline H2b: $\mathrm{COM} \times \mathrm{DU}$ & & & .042 & \\
\hline H2c: TO $\times$ DU & & & $.140^{* *}$ & \\
\hline H3a: CUS $\times$ CI & & & & -.066 \\
\hline $\mathrm{H} 3 \mathrm{~b}: \mathrm{COM} \times \mathrm{CI}$ & & & & $.093^{*}$ \\
\hline H3c: $\mathrm{TO} \times \mathrm{CI}$ & & & & $.102^{*}$ \\
\hline$R^{2}$ & .021 & .184 & .208 & .201 \\
\hline Adjusted $R^{2}$ & .011 & .164 & .183 & .174 \\
\hline$\Delta R^{2}$ & & $.162^{* * *}$ & $.025^{* *}$ & $.017^{*}$ \\
\hline
\end{tabular}

${ }^{* * *} p<.001,{ }^{* *} p<.01,{ }^{*} p<.05$.

1 indicates Chinese-foreign joint ventures and 0 represents local firms (e.g., state-owned, private, joint-stock enterprises). The logarithm of the number of employees of an SBU indicates firm size. Industry type is a dummy variable ( $1=$ high-tech industries, $0=$ other industries). A fouritem scale adapted from Jaworski and Kohli's (1993) work measures technological turbulence. Table 1 presents the means, standard deviations, and correlations of these measures.

\subsection{Construct validation}

This study uses confirmatory factor analysis with LISREL 8.7 to assess the convergent and discriminant validity of the focal constructs (i.e., strategic orientations, adaptive capability, market dynamics, and performance). A seven-factor confirmatory measurement model that includes all focal constructs results in a satisfactory fit: $\chi^{2}(209)=$ 444.42 , root mean squared error of approximation (RMSEA) $=.05$, comparative fit index $(\mathrm{CFI})=.94$, incremental fit index $(\mathrm{IFI})=.94$, and nonnormed fit index $(\mathrm{NNFI})=.93$. Furthermore, all factor loadings for each construct are significant $(p<.0001)$, and the composite reliability of all focal constructs exceeds the .60 benchmark (Bagozzi and Yi, 1988), which indicates good convergent validity of the scales. A series of chi-square difference tests of all the scales in pairs (21 tests) assesses discriminant validity by determining whether the freely estimated model is significantly superior to the constrained model (phi coefficient fixed at 1). In all cases, the chi-square differences are highly significant (e.g., customer orientation and competitor orientation: $\left.\Delta \chi^{2}(1)=55.14, p<.001\right)$, which suggests discriminant validity between the constructs (Anderson and Gerbing, 1988). Overall, the results suggest that the measurement scales are satisfactorily reliable and valid (see the Appendix).

\subsection{Common method bias}

A Harman one-factor test serves to assess the potential for common method bias in the data (Podsakoff and Organ, 1986). A factor analysis of the dependent and independent variables results in a solution that accounts for $69.32 \%$ of the total variance, and the first factor accounts for only $21.27 \%$ of the variance. Therefore, common method bias is unlikely to be a concern.

\section{Analysis and results}

\subsection{Main findings}

Because the model contains the interaction effects of strategic orientations and market dynamics, a moderated regression analysis is appropriate for testing the hypotheses (Jaccard, Turrisi, and Wan, 1990). To reduce multicollinearity between the main and interaction terms, this study first mean centers each scale that constitutes an interaction term, then multiplies the relevant mean-centered scales to obtain the interaction term (Jaccard et al., 1990).

A blockwise hierarchical approach assesses the R-square change of each model. The blockwise procedure results in four models, labeled Models 1-4 (see Table 2). Model 1 includes only the control variables as independent variables. Model 2 also includes the environmental constructs, Model 3 further comprises the interaction between strategic orientations and demand uncertainty, and Model 4 adds the interaction between strategic orientations and competitive intensity. This approach reduces the possible multicollinearity produced by correlations among interaction terms that contain the same constructs (cf. Zhou et al., 2007). As a result, the variance inflation factor values in the four models range from 1.01 to 1.53 , well below the usual 10.0 benchmark (Hair et al., 1998). Therefore, multicollinearity is not a concern in the analysis.

As Table 2 (Models 2-4) shows, the main effects of customer and technology orientations on adaptive capability are both positive and significant $(b=.198, p<.001 ; b=.193, p<.001$, respectively), in support of H1a and H1c. However, the main effect of competitor orientation is not significant in any model $(b=.010, p>.10)$, indicating no support for H1b.

$\mathrm{H} 2 \mathrm{a}-\mathrm{c}$ pertain to the moderating role of demand uncertainty (DU). As Model 3 indicates, the customer orientation $\times$ DU interaction is significantly negative $(b=-.165, p<.01)$, in support of $\mathrm{H} 2 \mathrm{a}$. In addition, the technology orientation $\times \mathrm{DU}$ interaction is positive and significant $(b=.140, p<.01)$, in support of $\mathrm{H} 2 \mathrm{c}$. However, the competitor orientation $\times \mathrm{DU}$ interaction shows no significant effects on adaptive capability ( $b=.042, p>.10$ ), and $\mathrm{H} 2 \mathrm{~b}$ receives no support.

$\mathrm{H} 3$ theorizes about the moderating role of competitive intensity $(\mathrm{CI})$. Contrary to the expectations of $\mathrm{H} 3 \mathrm{a}$, the results offer no support for the interaction between customer orientation and $\mathrm{CI}(\mathrm{b}=-.066, p>.10)$. Consistent with $\mathrm{H} 3 \mathrm{~b}$ and $\mathrm{H} 3 \mathrm{c}$, competitor orientation $\times \mathrm{CI}(\mathrm{b}=.093$, $p<.05)$ and technology orientation $\times \mathrm{CI}(\mathrm{b}=.102, p<.05)$ are both significantly positive.

Also as Table 2 shows, firm size relates positively to adaptive capability, suggesting that larger firms may achieve higher adaptive capability in China. However, neither firm type nor industry type has a significant bearing on a firm's adaptive capability.

\subsection{Post-hoc analysis}

Although technological turbulence represents an important element of market dynamics (e.g., Jaworski and Kohli, 1993), it might not affect the strategic orientation-adaptive capability relationships significantly in this context. Most industries in China rapidly update their technology levels with influxes of foreign investment (Isobe et al., 2000). As a result, technological changes are high overall and may not vary significantly across different industries. An ANOVA comparing technology turbulence across the six major industries indicates that technology turbulence does not vary significantly across the six industries in the sample $(\mathrm{F}=1.55, p>.05)$.

The findings in Table 1 also support this reasoning; of the three market dynamics elements (i.e., demand uncertainty, competitive 
intensity, and technology turbulence), technology turbulence exhibits the highest mean (5.5) and lowest standard deviation (0.9). Table 2 shows additional support; demand uncertainty fosters firm adaptive capability, and competition intensity lowers firm adaptive capability, but technology turbulence does not relate significantly to adaptive capability.

An additional regression analysis tests whether the interactions between strategic orientations and technology turbulence (TT) affect adaptive capability. This analysis shows that none of three interaction terms-customer orientation $\times \mathrm{TT}$, competitor orientation $\times \mathrm{TT}$, or technology orientation $\times$ TT - is significant $(b=.073, p>.10 ; b=-.023$, $p>.10 ; b=.007, p>.10$, respectively). Therefore, technology turbulence does not appear to be a key facet of market dynamics in influencing the effects of strategic orientations on adaptive capability in this research context.

\section{Discussion}

This study contributes to the literature in several ways. First, by identifying strategic orientation as an important driver of adaptive capability-a key element of dynamic capabilities-this study fills the research gap pertaining to how to build dynamic capability (Lavie, 2006). The integration of strategic orientation and adaptive capability perspectives illustrates how a firm's external interactions with customers, competitors, and technology affect its internal resource assortment and reconfiguration. In particular, both customer and technology orientations positively influence adaptive capability, which highlights the importance of understanding customers thoroughly and focusing on state-of-the-art technology to adapt to changing environments (Day, 1994; Hurley and Hult, 1998).

However, competitor orientation does not have a significant bearing on adaptive capability, perhaps because the fast changing nature of the Chinese market makes a competitor orientation less desirable. Facing the aggressive pressure of external changes, firms often have little time to react (Kumar, 1998). With a competitor orientation, firms tend to assume that competitors' actions are optimal and mimic them to reduce risks (Day and Nedungadi, 1994). However, a competitor's action may not be optimal. More critically, such an inclination may become gradually institutionalized as a routine and thus hamper firms' ability to renew or replace existing competences to adapt to changing environments. Moreover, because of the inadequate market and legal support in emerging economies, dysfunctional competitive behavior of firms, such as opportunistic, unfair, or even unlawful behavior, is widespread ( Li and Atuahene-Gima, 2001). Thus, information received from competitors may not be a reliable source of guidance for decision making and resource configuration, which makes a competitor orientation less relevant in building adaptive capability.

The second contribution of this research entails the examination of the contingency effects of strategic orientation and market dynamics. When market demand is increasingly uncertain, the role of customer orientation declines, whereas technology orientation becomes more prominent. The interaction between competitor orientation and demand uncertainty is not significant. Major competitors themselves may not know what customers need, so monitoring and catching up with competitors' actions likely cannot guide effective resource reconfigurations to adapt to demand changes in an appropriate and timely manner. Therefore, when customer preference is highly uncertain, focusing on advanced technology and new product introductions to shape customer preferences may be a better choice than following customer demand, which may not be predictable (Zhou et al., 2005). In times of intensified competition, both competitive and technology orientations help build adaptive capability. Therefore, to stand out from competitors, firms should closely monitor the competition and initiate actions quickly in response to their offerings. Alternatively, they could excel in their own technology capabilities and introduce truly unique products to achieve a highly differentiated position.

The finding regarding the negative interaction effect between customer orientation and demand uncertainty on adaptive capability is particularly noteworthy, because the result seems inconsistent with the widely held notion that customer orientation always benefits business activities (e.g., Deshpandé et al., 1993; Slater and Narver, 1998), as well as with previous empirical results that support the positive effects of customer orientation (e.g., Gatignon and Xuereb, 1997; Han et al., 1998). However, this result mirrors recent studies that indicate a possible dark side of customer orientation (e.g., Christensen and Bower, 1996; Voss and Voss, 2000). In rapidly changing environments, such as emerging economies, customer orientation may be a less reliable and efficient guide for resource allocations and reconfigurations. Moreover, customers are inherently myopic, in that they cannot foresee their needs and market trends (Hamel and Prahalad, 1994). Therefore, when they attempt to serve customers' existing needs, firms may risk losing the foresight needed to adapt quickly to external threats or opportunities, especially when customer needs change rapidly. In this sense, this study sheds new light on the role of customer orientation in the specific setting of emerging economies such as China.

The third contribution pertains to the new research context: the emerging economy of China. China offers a rich context to test the drivers of dynamic capability because its complex, fast changing nature makes adaptive capabilities critical for firms to survive and prosper in this market (Zhou and Li, 2007). As the world's largest emerging economy, China shares many characteristics with other emerging economies (Li, 2008; Peng, 2003). Findings based on the Chinese context therefore provide important direct and practical implications for firms operating in other emerging economies. For example, managers should understand that firms can undertake a customer or technology orientation, but not a competitor orientation, to build adaptive capability. More important, they must recognize the boundary conditions of these strategic orientations in emerging economies. When customer demand is highly uncertain, customer orientation is less effective, whereas technology orientation leads to improved adaptive capability. When competition intensifies, competitor and technology orientations are more desirable because they foster stronger adaptive capability.

This study also contains several limitations. First, consistent with Teece et al. (1997), this investigation focuses on the ability element of dynamic capabilities. However, Zollo and Winter (2002) view dynamic capability as a set of complicated processes and operating routines that reflect a learned and stable pattern rather than an ability. Further research should consider this approach to enrich the understanding of dynamic capabilities. Second, the measure of adaptive capability that this study uses encompasses both broader items about industry and market changes and a narrower focus on the World Trade Organization and e-commence. Additional research should develop more refined measures of adaptive capability by considering specific aspects, such as resource allocation and reconfiguration. Because this study uses a single-informant approach, common method bias also is a concern. Further investigation should use archival data or other sources of information to examine dynamic capabilities more accurately. Third, the Chinese market provides the study context because its fast changing nature makes dynamic capabilities more prominent for firms operating there. However, this nature also presents a potential limitation to the generalizability of the results to other emerging or developed economies. Fourth, the role of institutional factors (e.g., policies, regulations, industry norms) certainly deserves more attention, because unlike in Western countries, in China, the institutional factors that represent the rules of the game continue to evolve (Li et al., 2008; Peng, 2003). Therefore, further research should investigate how institutional factors drive firms' dynamic capabilities and how they interact with firm resources to influence dynamic capabilities and firm performance. 


\section{Appendix A. Measurement items and validity assessment}

\begin{tabular}{|c|c|}
\hline & $\begin{array}{l}\text { Standardized } \\
\text { factor loading }\end{array}$ \\
\hline \multicolumn{2}{|l|}{ Strategic orientation: } \\
\hline \multicolumn{2}{|l|}{ Customer orientation $\mathrm{CR}=.71$} \\
\hline $\begin{array}{l}\text { 1. Our competitive advantage is based on understanding } \\
\text { customers' needs }\end{array}$ & 0.53 \\
\hline 2. Our business objectives are driven primarily by customer satisfaction & 0.58 \\
\hline 3. We frequently and systematically measure customer satisfaction & 0.64 \\
\hline 4. We pay close attention to after-sales service & 0.60 \\
\hline \multicolumn{2}{|l|}{ Competitor orientation $\mathrm{CR}=.70$} \\
\hline 1. Our salespeople regularly share competitors' information & 0.63 \\
\hline 2. We rapidly respond to competitive actions that threaten us & 0.65 \\
\hline 3. Top management regularly discusses competitor's strategies & 0.65 \\
\hline \multicolumn{2}{|l|}{ Technology orientation $\mathrm{CR}=.73$} \\
\hline $\begin{array}{l}\text { 1. We use sophisticated technologies in our new product } \\
\text { development }\end{array}$ & 0.50 \\
\hline $\begin{array}{l}\text { 2. Our new products are always at the state of the art of the } \\
\text { technology }\end{array}$ & 0.55 \\
\hline $\begin{array}{l}\text { 3. Technological innovation, based on research results, is readily } \\
\text { accepted in our organization }\end{array}$ & 0.76 \\
\hline $\begin{array}{l}\text { 4. Technological innovation is readily accepted in our program/ } \\
\text { project management }\end{array}$ & 0.71 \\
\hline \multicolumn{2}{|l|}{ Adaptive capability $C R=.78$} \\
\hline 1. We are capable of reacting properly to changes in the market & 0.59 \\
\hline 2. Our existing competency can withstand changes in the industry & 0.81 \\
\hline $\begin{array}{l}\text { 3. Our existing competency can withstand the challenges brought } \\
\text { about by China's entry of WTO }\end{array}$ & 0.58 \\
\hline $\begin{array}{l}\text { 4. Our existing competency can withstand the challenges brought } \\
\text { about by the e-commerce trend }\end{array}$ & 0.56 \\
\hline \multicolumn{2}{|l|}{ Environment } \\
\hline \multicolumn{2}{|l|}{ Demand uncertainty $\mathrm{CR}=.70$} \\
\hline 1. It is difficult to understand consumers' expectations on a brand & 0.83 \\
\hline $\begin{array}{l}\text { 2. Consumers always look for novelty; they can never be loyal to a } \\
\text { single brand }\end{array}$ & 0.64 \\
\hline \multicolumn{2}{|l|}{ Competitive intensity $\mathrm{CR}=.61$} \\
\hline $\begin{array}{l}\text { 1. There are too many similar products in the market; it is very } \\
\text { difficult to differentiate our brand }\end{array}$ & 0.69 \\
\hline 2. This market is too competitive and price wars often occur & 0.60 \\
\hline \multicolumn{2}{|l|}{ Firm performance $C R=.83$} \\
\hline 1. Return on investment & 0.70 \\
\hline 2. Profit level & 0.79 \\
\hline 3. Sales growth in the past 2 years & 0.76 \\
\hline 4. Market share & 0.70 \\
\hline
\end{tabular}

Notes: $\mathrm{CR}=$ composite reliability.

\section{References}

Anderson JC, Gerbing DW. Structural equation modeling in practice: a review and recommended two-step approach. Psychol Bull 1988;103(3):411-23.

Atuahene-Gima K. An exploratory analysis of the impact of market orientation on new product performance: a contingency approach. J Prod Innov. Manage 1995;69:61-83.

Bagozzi RP, Yi Y. On the evaluation of structural equation models. J Acad Mark Sci 1988:16(1):74-94.

Benner MJ. Dynamic or static capabilities? Process management and adaptation to technological change. Working paper; 2006.

BusinessWeek. The iPhone not a success?; 2007. http://www.businessweek.com/ the thread/brandnewday/archives/2007/06/the iphone_not.html.

Chakravarthy BS. Adaptation: a metaphor for strategic management. Acad Manage Rev 1982;7(1):35-44.

Christensen CM, Bower JL. Customer power, strategic investment, and the failure of leading firms. Strateg Manage J 1996;17(3):197-281.

Cohen WM, Levinthal DA. Absorptive capacity: a new perspective on learning and innovation. Adm Sci Q 1990;35:128-52.

Day GS. The capabilities of market-driven organizations. J Mark 1994;58(4):37-52.

Day GS, Nedungadi P. Managerial representations of competitive advantage. J Mark 1994;58(2):31-44.

Day GS, Wensley R. Assessing advantage: a framework for diagnostic competitive superiority. J Mark 1988;52(2):1-20.
Deshpandé R, Farley JU, Webster FE. Corporate culture, customer orientation, and innovativeness. J Mark 1993;57(1):23-7.

Eisenhardt KM, Martin JA. Dynamic capabilities: what are they? Strateg Manage J 2000;21 (10-11):1105-21.

Gatignon H, Xuereb JM. Strategic orientation of the firm and new product performance. J Mark Res 1997;34(1):77-90.

Gibson GB, Birkinshaw J. The antecedents, consequences, and mediating role of organizational ambidexterity. Acad Manage J 2004;47(2):209-26.

Gilbert CG. Unbundling the structure of inertia: resource versus routine rigidity. Acad Manage J 2005;48(5):741-63.

Ginsberg A, Venkatraman N. Contingency perspectives of organizational strategy: a critical review of the empirical research. Acad Manage Rev Vol 1985;10(3):421-34.

Griffith DA, Harvey MG. A resource perspective of global dynamic capability. J Int Bus Stud 2001;32(3):597-606.

Griffith DA, Noble SM, Chen OM. The performance implications of entrepreneurial proclivity: a dynamic capabilities approach. J Retail 2006;82(1):51-62.

Hair JF, Anderson RE, Tatham RL, Black WC. Multivariate Data Analysis. New Jersey: Prentice Hall; 1998.

Hamel G, Prahalad CK. Competing for the Future. Boston: Harvard Business School Press; 1994.

Han JK, Kim N, Srivastava R. Market orientation and organizational performance: is innovation a missing link? J Mark 1998;62(4):30-45.

Hurley RF, Hult GTM. Innovation, market orientation, and organizational learning: an integration and empirical examination. J Mark 1998;62(3):42-52.

Isobe T, Makino S, Montgomery DB. Resource commitment, entry timing, and market performance of foreign direct investments in emerging economies: the case of Japanese international joint ventures in China. Acad Manage J 2000;43 (3):468-84.

Jaccard J, Turrisi R, Wan CK. Interaction Effects in Multiple Regression. Newbury Park, CA: Sage Publications; 1990

Jaworski BJ, Kohli AK. Market orientation: antecedents and consequences. J Mark 1993;57 (3):53-70.

Kirca AH, Jayachandran S, Bearden WO. Market orientation: a meta-analytic review and assessment of its antecedents and impact on performance. J Mark 2005;69 (2):24-41.

Kumar K, Subramanian R, Yauger C. Examining the market orientation-performance relationship: a context-specific study. J Manage 1998;24(2):201-33.

Lavie D. Capability reconfiguration: an analysis of incumbent responses to technological change. Acad Manage Rev 2006;31(1):153-74.

Leonard-Barton D. Core capabilities and core rigidities: a paradox in managing new product development. Strateg Manage J 1992;13:111-25 (summer).

Lenox M, King A. Prospects for developing absorptive capacity through internal information provision. Strateg Manage J 2004;25(4):331-45.

Li JJ. How to retain local senior managers in international joint ventures: the effects of alliance relationship characteristics. J Bus Res 2008;61(9):986-94.

$\mathrm{Li} \mathrm{H}$, Atuahene-Gima K. Product innovation strategy and the performance of new technology ventures in China. Acad Manage J 2001;44(6):1123-34.

Li JJ, Poppo L, Zhou KZ. Do managerial ties in China always produce value? Competition, uncertainty, and domestic vs. foreign firms. Strateg Manage J 2008;29(4):383-400.

Li JJ, Zhou KZ, Shao AT. Competitive strategy, managerial ties, and profitability of foreign firms in China: An interactive perspective. J Int Bus Stud 2009;40(2):339-52.

Makadok R. Toward a synthesis of the resource-based and dynamic-capability views of rent creation. Strateg Manage J 2001;22(5):387-401.

Mckee DO, Varadarajan PR, Pride WM. Strategic adaptability and firm performance: a market-contingent perspective. J Mark 1989;53(3):21-35

Narver JC, Slater SF. The effect of a market orientation on business profitability. J Mark 1990;54(4):20-35.

Peng MW. Institutions, institutional change and economic performance. Acad Manage Rev 2003;28:275-96.

Podsakoff PM, Organ DW. Self-reports in organizational research: Problems and prospects. J Manage 1986;12(4):531-44.

Porter ME. Competitive Strategy. New York: The Free Press; 1985.

Rumelt RP, Schendel D, Teece D. Fundamental Issues in Strategy. Cambridge, MA: Harvard Business School Press; 1991.

Slater SF, Narver J. Does competitive environment moderate the market orientationperformance relationship? J Mark 1994;58(1):46-55.

Slater SF, Narver J. Customer led and market oriented: let's not confuse the two. Strateg Manage J 1998;19(10):1001-6.

Teece DJ, Pisano G, Shuen A. Dynamic capabilities and strategic management. Strateg Manage J 1997;18(7):509-33.

Tsai W. Knowledge Transfer in intraorganizational networks: effects of network position and absorptive capacity on business unit innovation and performance. Acad Manage J 2001;44(5):996-1004.

Tuominen M, Rajala A, Moller K. How does adaptability drive firm innovativeness? J Bus Res 2004:57:495-506.

Tushman M, Anderson P. Technological discontinuities and organizational environments. Adm Sci Q 1986;31(3):439-65.

Von Hippel E. Sources of Innovation. New York: Oxford University Press; 1988.

Voss G, Voss Z. Strategic orientation and firm performance in an artistic environment. J Mark 2000;64(1):67-83

Workman JP. Marketing's limited role in new product development in one computer system firm. J Mark Res 1993;30(4):405-21.

Zaheer A, Bell GG. Benefiting from network position: firm capabilities, structural holes, and performance. Strateg Manage J 2005;26(9):809-25.

Zahra S, George G. Absorptive capacity: a review, reconceptualization and extension. Acad Manage Rev 2002;27(2):185-203. 
Zhou KZ, Li CB. How does strategic orientation matter in Chinese firms. Asia Pac J Manag 2007;24(4):447-66.

Zhou KZ, Yim BC, Tse DK. The effects of strategic orientations on technology- and market-based breakthrough innovations. J Mark 2005;69(2):42-60.

Zhou KZ, Tse DK, Li JJ. Organizational changes in emerging economies: drivers and consequences. J Int Bus Stud 2006;37:248-63.
Zhou KZ, Brown JR, Dev CS, Agarwal S. The effects of customer and competitor orientations on performance in global markets: a contingency analysis. J Int Bus Stud 2007;38(2):303-19.

Zollo M, Winter SG. Deliberate learning and the evolution of dynamic capabilities. Org Sci 2002;13(3):339-51. 